\title{
Research and Implementation of Experimental Teaching Platform System Based on HTML5 Mobile
}

\author{
Liang Zhao \\ Jilin Institute of Chemical Technology \\ Jilin City, Jilin Province, China
}

\author{
Shuangyuan $\mathrm{Li}^{*}$ \\ Jilin Institute of Chemical Technology \\ Jilin City, Jilin Province, China \\ Email: lsy@jlict.edu.cn
}

\begin{abstract}
With the continuous progress of society and the rapid development of information, mobile terminal technology plays an important role in our life. Now the mobile terminal is an ultra-small computer system, which can realize rich functions and bring good teaching effects in classroom teaching and distance teaching. This paper realizes the interactive function of experimental teaching network through the design method of HTML5 in the mobile terminal. Realize the online interactive learning, experimental teaching and other functions of the platform. Html5 combined with DIV+CSS, dynamic web technology PHP, database MySQL, to achieve administrator authority division, information release, management, delete, interaction and other functions. HTML5 platform enables students to take the initiative in learning, and students, teachers and teaching resources achieve three-way interaction.
\end{abstract}

Keywords-Course management; Teaching; Mobile platform; HTML5. MYSQL

\section{INTRODUCTION}

Nowadays, the popularity of mobile network make the learners can learn through mobile terminal, greatly improve the learning efficiency, refers to the mobile end can be used in the mobile computing devices, such as mobile phones, tablets, laptops, but generally refers to the multi-function smartphones and tablets, with the throughout of network and technology, will enable us to the real mobile era, on the other hand, with the development of integrated circuit technology, the mobile end processing power is more and more strong, will become more and more information of the mobile platform. [1]

Mobile terminal experimental teaching platform requires learners to be able to interact with the knowledge content related to learning platform, mobile devices and other teaching activities. Mobile terminal experimental teaching platform is built on the characteristics of smart phones and mobile experimental teaching platform is extensive. Its performance is highly adaptable. The social aspect of the learning environment should follow the principle of making the operating system easier and more convenient for users. [2]

\section{DESIGN PRINCIPLES}

\section{A. Interface and navigation design}

The friendly interface and clear navigation design

Fund projects: The "13th Five-Year Plan" for Education Science in Jilin Province "Research on Internet + experimental teaching innovation model of artificial intelligence” (approval no GH180442). principles are designed to improve the learner's experience. In the first place, design the interface and navigation. In order to facilitate the use of learners, quick jump and clear navigation should be done in navigation, which is convenient to use and improve the efficiency of learners. Does not take up a lot of memory space on the user's mobile device. [3]

\section{B. Applicability of knowledge content}

Learning platform of the contents of the knowledge should be easy to learn, can make learners to take an interest in learning, improve the efficiency of learning, the learners can easily enter the learning state, will not grow tired of learning, but also to enhance learners' self-learning ability, strengthen the interaction and learners, enhance knowledge of the learners to master the ability of content should be clear and concise design, after class to master the way to the point. [4]

\section{User convenience}

As it is on a mobile device, the content of the mobile learning platform is mainly online viewing, online Q\&A and online solution. Avoid heavy user input to prevent crashes. In this way, learners can clearly grasp the learning content and the next step of learning objectives, so as to provide operational response and feedback for learners, and display corresponding processing results and hints to learners. [5]

\section{EXPERIMENTAL TEACHING}

\section{A. Experimental teaching content}

In the experimental teaching system, according to the training needs of students, to shape the students' ability of self operation, self - research ability and self - experiment ability. On the basis of html5, experiment teaching is realized through mobile terminal. The experimental course system is mainly for cultivating students' observation and practical ability, and cultivating students' pragmatic attitude towards scientific experiments. Through the basic experimental project, the improvement of experimental project, the research of experimental project and the comprehensive cultivation of experimental project, students become professional talents with research and development ability and high comprehensive quality. Experimental teaching platform is divided into experimental teaching levels: basic verification of experiments, comprehensive design of experiments and innovative research of experiments. Experimental teaching is an indispensable and 
important part in the process of science teaching.Compared with theoretical teaching, it provides operability, which can not be replaced by theoretical teaching, and it is also an extension and supplement of theoretical teaching, a test and promotion of theoretical teaching, and an important link to train students to combine theory with practice, cultivate independent analysis of problems, solve problems and improve practical ability. Theory teaching and experiment teaching are inseparable, especially computer teaching. [8]

\section{B. Advantages of experimental teaching}

- Experimental teaching adopts more direct, vivid and concrete teaching methods than theoretical teaching, which effectively expands the space for completing teaching tasks and makes teaching, learning and practice carry out together. Therefore, it is more effective than theoretical teaching to mobilize students' interest in learning, easier for students to accept. The mobile terminal experiment teaching not only reduces the problems of the place, but also provides the problems that students will not apply after learning, which makes the knowledge they receive more impressive and easier to understand. Through experimental teaching, students can digest theoretical knowledge and consolidate what they have learned, so that they can get twice the result with half the effort, more effectively convert what they have learned into their own knowledge and learn with high quality. [9]

- Due to the lack of effective practical support for theoretical learning, what students often learn in theoretical teaching is abstract and impractical, especially those doubts, difficulties and key problems that they need to understand and digest after class, which can only be digested abstractly and imaginatively. This digestion is "air to air".Therefore, despite the efforts of both teachers and students, the teaching effect is not always ideal. However, experimental teaching enables students to find and solve problems under the guidance of teachers.

- The biggest characteristic of experimental teaching is that it is based on "doing", so that students have the opportunity to fully practice and demonstrate their working ability, create skills and display their talents. At the same time, teachers can also learn to examine the contents and methods they teach students in experimental teaching from the perspective of students, and find out the details that they did not pay attention to in the past, as well as the details that need to be strengthened and improved in future classroom teaching.

\section{The present situation of experimental teaching}

The current situation in foreign countries attaches great importance to experiment and exploration, and highlights the characteristics of courses:
(1) pay attention to the cultivation of students' scientific literacy, with the cultivation of innovation ability and practical ability as its core content

(2) pay attention to the understanding of the scientific inquiry process and the training of scientific experimental methods;

(3) attach great importance to experimental teaching.

Domestic status:

Experimental teaching experience ups and downs, but always not really out of the ideal "circle".Quality education thunder enough big, but the rain is a little small, ideal and reality in contradiction maintain.

\section{Design of interactive experimental teaching}

In an interactive learning environment, the process of learning knowledge is active learning, communicating and sharing with others. When designing the interaction, students should be guided to continuously innovate their knowledge. Interaction refers to the interaction between learners, mobile device learning platforms, teachers and students in order to create a good interactive environment. Let teachers and students and teaching resources through the platform connection, so as to achieve a qualitative leap, to build a harmonious learning environment.In the process of interaction, the learning efficiency of students can be improved so that students can be interested in knowledge and promote learning. [9]

\section{E. Learning Course Resources}

Mobile learning a lot of differences with the traditional classroom learning, mobile more convenient than traditional learning in teaching a lot of resources at the same time also is rich, but in the teaching mode has the very big difference, especially the organization form of knowledge, so mobile teaching-learning resources collected from the problem of learning, through modular processing all kinds of knowledge, is derived in order to make the teaching more clear teaching goal. Mobile learning platforms should combine a large number of resources, keep the content short and clear, and set learning goals to promote learning efficiency.

\section{FUNCTION ANALYSIS OF INTERACTIVE MOBILE LEARNING PLATFORM BASED ON HTML5}

HTML5 is the fifth generation of hypertext language. HTML5 has great advantages in developing mobile learning platform, which can adapt to intelligent devices of different operating systems and prevent compatibility problems of mobile learning platform due to problems of the user operating system. Mobile experimental teaching platform based on HTML5 has good experience and adaptability, and does not occupy the storage space of users' mobile devices. Moreover, the platform is convenient to develop, with low cost and small workload. 
HTML5 features animation and multimedia features, can achieve the organic combination of text, pictures, tables, audio, video and color. Meanwhile, CSS3 supports font embedding, layout and animation functions, enriching the learning content form of HTML5 online courses, which can greatly attract students' attention and improve learning effect. At the same time, HTML5 also has better learning interaction, supporting cross-platform learning, offline learning and other features. [10]

\section{A. HTML5 mobile development status analysis}

HTML is an important markup language for describing web documents and an important way to build and present Internet content.HTML5 combines the Internet's most advanced technologies to effectively increase the Internet's application set. It is also prominent in the development of mobile devices and their relationships.HTML5 creates single-element tables for mobile devices. At present, some mobile devices have prominent touch screen functions. It can realize the data input function of virtual touch screen tools and improve the input efficiency.HTML5 optimizes the shortcomings of the original software. This technique is also widely used and is very convenient for drawing ICONS and downloading information. In the teaching of HTML5 mobile development course, it has become the new content of teaching knowledge. In order to improve the teaching quality at this level, it is necessary to implement new teaching methods, which is also of positive significance for the technical upgrading and optimization of HTML5.

\section{B. Mobile platform function}

In terms of experimental teaching methods, problems should be combined with two-way communication and user sharing. From the technical point of view, as long as the simple database sharing technology is adopted, there is no need to use methods such as view sharing or packet uploading to achieve the specified path transmission of subsystem data to data center. Between the data center and the subsystem, the port setting requires one-way data transfer, so the data forms a cloud-like storage space, passively receiving data information, and accessing from different users. It is difficult to check and control the data transmission rate, security, accuracy or correlation with logical algorithms. Once the subsystem data changes, the source data or other system data in the associated data changes synchronously accordingly. The system platform can actively manage all the data interaction process in the multi-direction secure transmission of data, not just the original passive massive database.

\section{SYSTEM RESEARCH AND IMPLEMENTATION}

The overall design of the teaching platform system is divided into three types of users: students, teachers and administrators, as shown in Fig. 1.

Students can register, login, courseware and course inquiry, cache of course resources, test, Q\&A and other online functions. If you have a difficult problem, you can leave a message to the teacher on the message board, or if you think there is something you need to improve, you can leave a message to the teacher and give your own Suggestions.
Teachers' necessary authority is: register, log in the background, teacher users log in the background, can upload and release courseware, answer questions online, answer students' questions on the message board, upload and release teaching video.

Administrator necessary authority is: after logging into the background, can manage courses, teachers and users and other information. Achieve administrator authority division, information release, management, delete, interaction and other functions. [11]

Research and implementation of mobile terminal experimental teaching system based on HTML5

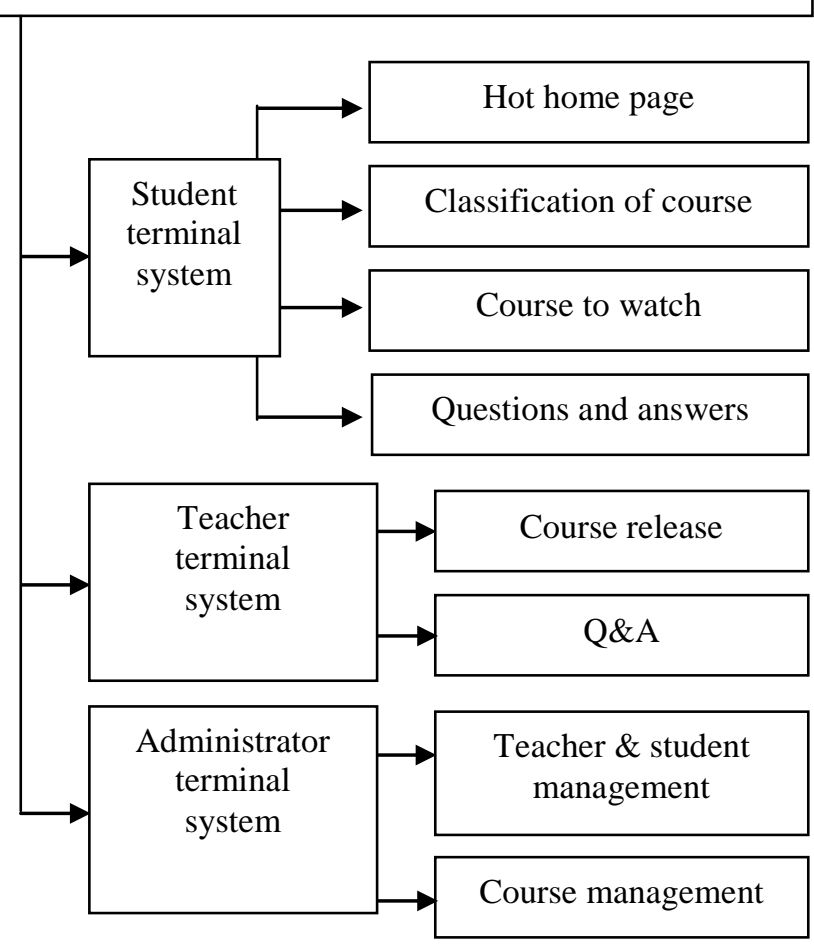

Fig. 1. Learning platform system module management.

\section{A. The system design is divided into two parts}

System design is divided into front and background two parts. The front end is the interface between the system and users, providing users with video courses, courseware and course resources download, experimental analysis, online testing, online Q\&A and other functions. Users can learn after registration. Unregistered users will not be able to learn. In the registration process, users can choose three roles of students, teachers and administrators to log in through professional titles, and the system will query and verify in the data table. The system mainly USES HTML5 and CSS3 to customize the uniform page color style, establish the page font, define the main size, and customize the page body. Video and audio playback functions can be realized through HTML5 tags, as shown in Fig. 2.

Students learn by watching video and courseware uploaded by teachers, test the learning effect, and solve the problems 
they don't understand and their own opinions by leaving messages and answering questions online. [12]

Teachers can upload video courseware to reduce the burden of traditional classes, and answer questions and messages online or carry out video teaching to teach.

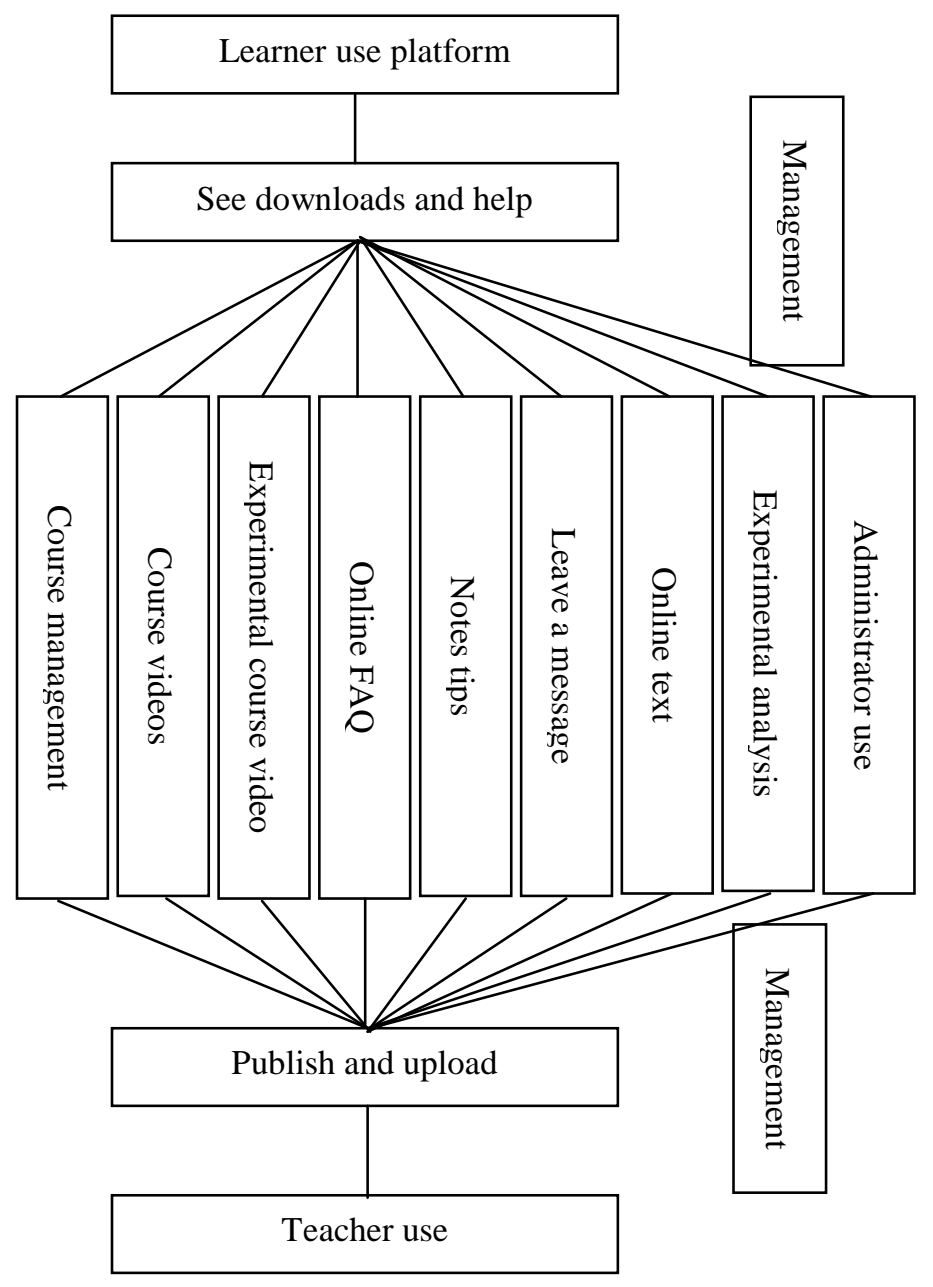

Fig. 2. Learning platform work flow chart.

\section{CONCLUSION}

In addition to the main parts of the program design principles, interactive design, mobile platform, experimental teaching, system design implementation, html5 function implementation and so on, this paper also introduces html5 related information and recent situation, the momentum and development of the mobile platform.

Through the preparation and consulting of this paper, I understand that mobile terminal experimental teaching is a reform of teaching methods in the future and a development trend. Rich presentation forms of knowledge content and interactive learning can attract learners to participate in the learning of mobile terminal teaching, enjoy the fun of learning and improve learning efficiency.

The development of HTML5 mobile terminal experimental teaching platform is analyzed, and its interactive characteristics are obvious. This mobile interactive learning platform does not need high development costs, and can ensure the adaptability of the system, relatively low requirements on mobile terminals, and can display different learning content on the platform. With the development of the Internet, HTML5 mobile terminal experimental teaching platform has a broad prospect.

\section{REFERENCES}

[1] Li Luo, Hua Wang, Feng Liu. Design and implementation of smart campus APP client based on HTML5 [J]. Computer Knowledge and Technology, 2018, (15):90-91. (In Chinese)

[2] Tianqi Liu. HTML5 and the future WEB application platform [J]. Yinshan Academic Journal: Natural Science Edition, 2014 (2): 55-58.(In Chinese)

[3] Yingchao Li, Hongtao Zhang, Chaojun Wu, Junfeng Chen, Jintao Yang, Yushan Su. Analysis of Interactive Mobile Learning Platform Based on HTML5 [J]. Computer Programming Skills \& Maintenance, 2018(06): 85-86+98. (In Chinese)

[4] Bao Chen. Research on Mobile Learning Platform Based on HTML5 [J] Wireless Interconnect Technology, 2017(18):98-99. (In Chinese)

[5] Xueming Zhao, Ye Ying, Wang Qian. Based on HTML5 design and implementation of interactive mobile learning platform [J]. Heilongjiang Science and Technology Information, 2017 (03): 197-199. (In Chinese)

[6] XueMing, Zhao, Gang Wang. Research on Interactive Mobile Learning Platform Based on HTML5 [J]. Modern Educational Technology, 2016.26(09): 106-112. (In Chinese)

[7] Zhaocui Li. Design and Implementation of an Online Learning System Based on HTML5 [J] . Science and Technology, 2018(36):102. (In Chinese)

[8] Limin Zhang, Ximing Wang. Construction and Research of Online Open Course Based on Students' Core Competence - Taking the Open Course of HTML5 Web Design as an Example [J] . Science and Technology, 2018(34):236. (In Chinese)

[9] Bianchen Chen, Yinghan Wang. Based on HTML5 research campus of mobile service platform and implementation [J]. Wireless Internet Technology, 2018,15 (11): 90-91. (In Chinese)

[10] Yafang Zhi. Research on mobile advertising based on HTML5 [J]. Computer fans, 2018 (07): 246. (In Chinese).

[11] Xanthopoulos, S, S. Xinogalos in the HTML5 Mobile App Development [C]. Symposium ON Computer Language S., 2015.

[12] Zbick J, Nake I, Jansen M, et al. mLearn4web: a web-based framework to design and deploy cross-platform mobile applications[C]. International Conference on Mobile \& Ubiquitous Multimedia. 2014

[13] Zbick J, Nake I, Milrad M, et al. A Web-Based Framework to Design and Deploy Mobile Learning Activities: Evaluating Its usability, Learnability and Acceptance [C]. IEEE International Conference on Advanced Learning Technologies. 2015 